\title{
Early diagnosis of lentivirus-induced infiltrative lung disease in sheep by high resolution computed tomography
}

\author{
J.L. Cadoré*, P. Loubeyre**, S. Vuillermoz*, I. Court-Fortune*, \\ D. Revel**, J.F. Mornex*
}

Early diagnosis of lentivirus-induced infiltrative lung disease in sheep by high resolution computed tomography. J.L. Cadoré, P. Loubeyre, S. Vuillermoz, I. Court-Fortune, D. Revel, J.F. Mornex. (CERS Journals Ltd 1997.

ABSTRACT: The visna-maedi lentivirus can induce an interstitial pneumonitis in sheep, and provides a convenient example to study natural or experimental lentiviral pathology. We wanted to determine whether high resolution computed tomography (HRCT) is able to detect early morphological changes following lentiviral infection in the lungs.

Spontaneously infected adult sheep $(n=3)$ and experimentally infected lambs $(n=5)$ were compared to uninfected controls $(n=4)$.

The HRCT scans generally showed abnormal features in infected animals, including: increased parenchymal density; alveolar oedema; thickened interlobular septa; and increased density in peribronchiolar areas. HRCT was more sensitive than chest radiography for the early diagnosis of interstitial pneumonitis, although one sheep with advanced disease and radiographic and histopathological abnormalities had a paradoxically normal scan. One control animal showed minor abnormalities on scanning, which were probably due to the procedure used for anaesthesia. The HRCT observations were confirmed by postmortem histological examination of the lungs.

In conclusion, high resolution computed tomography provides a noninvasive means of following the development of lung pathology in a natural ovine model of lentiviral disease.

Eur Respir J 1997; 10: 1456-1459.
*Laboratoire associé de recherche sur les Lentivirus chez les Petits ruminants, INRA and Ecole vétérinaire de Lyon and Laboratoire d'immunologie et de biologie pulmonaire, INSERM CJF 93-08, Faculté de Médecine Grange Blanche, Université Claude Bernard, Service de pneumologie, Hôpital Louis Pradel, Hospices Civils de Lyon, France. **Laboratoire CREATISURA CNRS 1216, Université Claude Bernard, Département de radiologie, Hôpital Louis Pradel, France.

Correspondence: J.L. Cadoré, Ecole vétérinaire de Lyon, 1 av. Bourgelat, 69280 Marcy l'Etoile, France

Keywords: High resolution computed tomography, interstitial lung disease, lentivirus, visna-maedi virus

Received: April 251996

Accepted after revision April 241997

Supported in part by grants from: Agence Nationale de Recherche contre le SIDA.
Visna-maedi virus is a naturally occurring sheep lentivirus, which induces chronic and/or degenerative diseases affecting lungs, brain, joints and mammary glands $[1,2]$. An interstitial pneumonitis, similar to that reported in humans infected by human immunodeficiency virus1 (HIV-1) may occur in spontaneously or experimentally infected sheep. The lung pathology is characterized by alveolitis, peribronchovascular lymphoid nodules, alveolar wall thickening, and myomatosis [3, 4]. We have evaluated whether high resolution computed tomography (HRCT) is capable of evaluating morphological changes in interstitial pneumonitis in a study of early lesions induced by experimental infection of newborn lambs, and of late manifestations of disease in naturally infected adult sheep.

\section{Materials and methods}

\section{Experimental infection of newborn lambs}

Newborn lambs were separated from their dams before suckling to prevent colostral transmission of the virus, and were divided into two groups. One group of animals $(n=5)$ were transtracheally inoculated, as described by LAIRMORE et al. [5], with visna-maedi virus (5×
$10^{5} 50 \%$ tissue culture infection dose (TCID50) in 5 $\mathrm{mL}$ ) obtained by productive replication of low-passage field isolates $[6,7]$ in ovine skin fibroblast cultures (IDO5; Rhône-Merieux, France). The control group $(n=4)$ was inoculated with the same volume of saline. To prevent horizontal transmission, animals were housed separately for 3 months, after which they were slaughtered in accordance with French regulations, as approved by the French Ministry of Agriculture (authorization No. 05876).

\section{Spontaneously infected adult sheep}

Three adult sheep were obtained from infected flocks, and viral infection was confirmed by serology. These animals were at least 5 yrs old, and had presented clinical features of interstitial pneumonitis with cough and dyspnoea on effort for 6-12 months. After slaughter, pathological and virological examinations of lungs were performed.

\section{Detection of lentivirus}

Postmortem bronchoalveolar lavage (BAL) was performed as described previously [8], and the resulting cells were co-cultured with permissive ovine skin fibroblasts 
(IDO5). Lentiviral infection was demonstrated by the appearance of syncytia with more than 8 nuclei-cell-1 after 10-30 days of co-culture. Retroviral infection was confirmed by reverse transcriptase measurements of the culture supernatants [9].

\section{Chest radiography}

Chest radiographic examination was performed before slaughter, using a Pandoros Optimatic (Siemens ${ }^{\mathrm{TM}}$, Lyon, France) system with high-speed screens and a moving parallel grid, on conscious animals in lateral and dorsal recumbency.

\section{HRCT of the chest}

All animals were examined once by HRCT immediately after chest radiography. The sheep were anaesthetized by intravenous perfusion of a $2 \%$ pentobarbital solution, and were positioned prone on the HRCT bed (CGR Thompson 12,000 ${ }^{\mathrm{TM}}$, Buc, France). Scans were taken during artificial suspension of ventilation. Ten slices, each $1.5 \mathrm{~mm}$ thick and spaced $15 \mathrm{~mm}$ apart on a $512 \times 512$ matrix, were acquired to include the complete lung from apex to diaphragm for each animal. Resolution was maximized by use of the "bone" algorithm for image reconstruction. The images were separately evaluated by two independent observers.

\section{Pathology}

Lung tissue specimens taken at autopsy were fixed in Bouin's solution and embedded in paraffin. Sections $(5 \mu \mathrm{m})$ were stained with haematoxylin, phloxine and safranin. The diagnosis of interstitial pneumonitis was based on the presence and importance of perivascular or parenchymal lymphoid nodules, luminal or interstitial alveolitis, myomatosis and fibrosis.

\section{Results}

Chest radiography indicated interstitial lung disease in all three late-stage spontaneously infected adult sheep, but was normal in the four control animals, and in 4 of the 5 experimentally infected lambs.

One of the experimentally infected lambs (No. 3) showed thickened peribronchiolar areas, principally in the lower lobes. In contrast, HRCT scans showed abnormal features in all of the spontaneously infected animals, with the exception of one adult sheep which had a paradoxically normal scan. The control animals showed no significant deviations from normality, except that No. 9 had an anterior-to-posterior density gradient. Only this animal was anaesthetized in a dorsal position, which might account for the observation.

The experimentally infected lambs varied in the type and intensity of the lesions, as shown in table 1. In lambs Nos. 1 and 2, the lesions were represented only by patchy areas of increased density (not explained by declivity), which were interpreted as minor oedema.
Table 1. - Results of high resolution computed tomography (HRCT) in experimentally infected and control lambs

\begin{tabular}{|c|c|c|c|c|}
\hline $\begin{array}{l}\text { Lamb } \\
\text { No. }\end{array}$ & $\begin{array}{l}\text { Increased } \\
\text { global } \\
\text { parenchymal } \\
\text { density }\end{array}$ & $\begin{array}{c}\text { Alveolar } \\
\text { oedema }\end{array}$ & $\begin{array}{c}\text { Thickened } \\
\text { interlobular } \\
\text { septa }\end{array}$ & $\begin{array}{l}\text { Thickened } \\
\text { peri- } \\
\text { bronchiolar } \\
\text { area }\end{array}$ \\
\hline
\end{tabular}

\begin{tabular}{|c|c|c|c|c|}
\hline \multicolumn{5}{|c|}{ Experimentally infected lambs } \\
\hline 1 & + & \pm & - & - \\
\hline 2 & - & + & - & - \\
\hline 3 & + & - & - & + \\
\hline 4 & + & - & + & + \\
\hline 5 & + & - & + & + \\
\hline \multicolumn{5}{|c|}{ Control lambs } \\
\hline 6 & - & - & - & - \\
\hline 7 & - & - & - & - \\
\hline 8 & - & - & - & - \\
\hline 9 & \pm & - & - & - \\
\hline
\end{tabular}

+: present; \pm : present but minor; -: negative.

These areas of increased density were not demarcated by thickened interlobular septa, unlike other cases (lambs Nos. 3-5) where the changes in morphology were more substantial, with thickened interlobular septa and peribronchiolar areas. In sheep Nos. 3 and 4, the lesions occurred principally in the lower lobes and the peribronchiolar area was irregular and thickened with a cortical distribution, particularly on the left side (fig. 1).

The HRCT observations (table 1) were confirmed by anatomo-pathological examination of postmortem lung tissue specimens (table 2). Thickened interlobular septa were seen in all infected lambs, and peribronchovascular lymphoid nodules were frequent in lambs Nos. 3-5, but less common in lambs Nos. 1 and 2. Intraparenchymatous lymphoid nodules and lymphoid nodules in the mediastinal nodes were seen only in lamb No. 5, and myomatosis was never observed. Control animals showed only very small and sparse peribronchovascular lymphoid nodules (table 2).

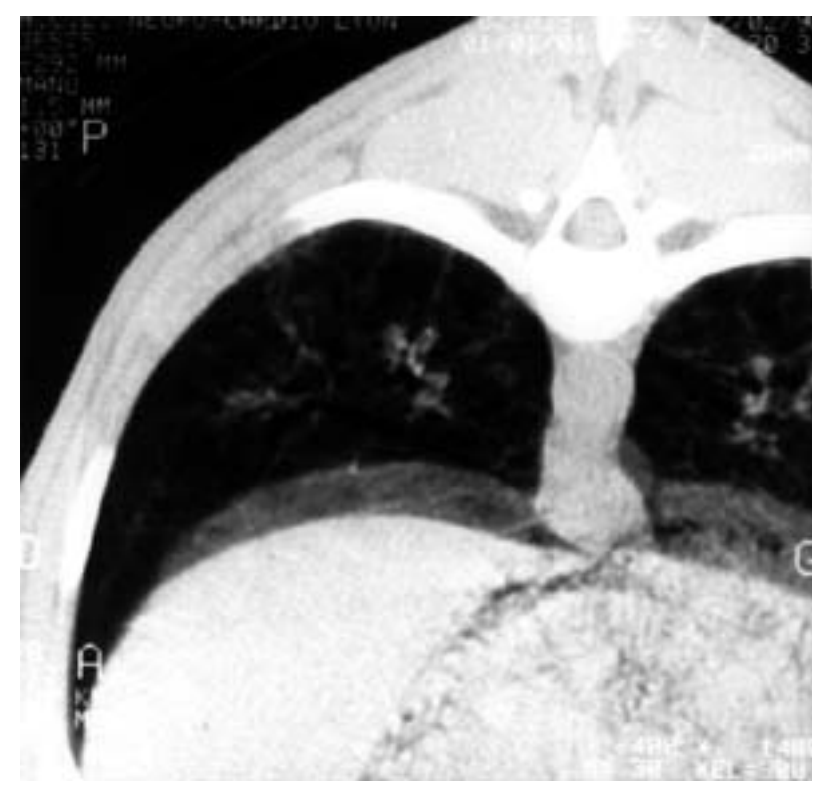

Fig. 1. - High resolution computed tomography (HRCT) performed in experimentally infected lambs. An irregularly thickened peribronchiolar area is visible, with a cortical distribution, particularly on the left side. 
Table 2. - Pathology in experimentally infected lambs and in control lambs

\begin{tabular}{lccccc}
\hline Lamb & $\begin{array}{c}\text { Thickened } \\
\text { interlobular } \\
\text { septa }\end{array}$ & $\begin{array}{c}\text { Intraparen- } \\
\text { chymatous } \\
\text { lymphoid } \\
\text { nodules }\end{array}$ & $\begin{array}{c}\text { Peribroncho- } \\
\text { vascular } \\
\text { nodules }\end{array}$ & Myomatosis & $\begin{array}{c}\text { Lymphoid } \\
\text { nodules in } \\
\text { mediastinal } \\
\text { nodes }\end{array}$ \\
\hline
\end{tabular}

\begin{tabular}{|c|c|c|c|c|c|}
\hline \multicolumn{6}{|c|}{ Experimentally infected lambs } \\
\hline 1 & \pm & - & \pm & - & - \\
\hline 2 & \pm & - & \pm & - & - \\
\hline 3 & \pm & - & + & - & - \\
\hline 4 & \pm & - & + & - & - \\
\hline 5 & \pm & \pm & + & - & - \\
\hline \multicolumn{6}{|c|}{ Control lambs } \\
\hline 6 & - & - & \pm & - & - \\
\hline 7 & - & - & \pm & - & - \\
\hline 8 & - & - & - & - & - \\
\hline 9 & - & - & \pm & - & - \\
\hline
\end{tabular}

+: present; \pm : present but minor; -: negative.

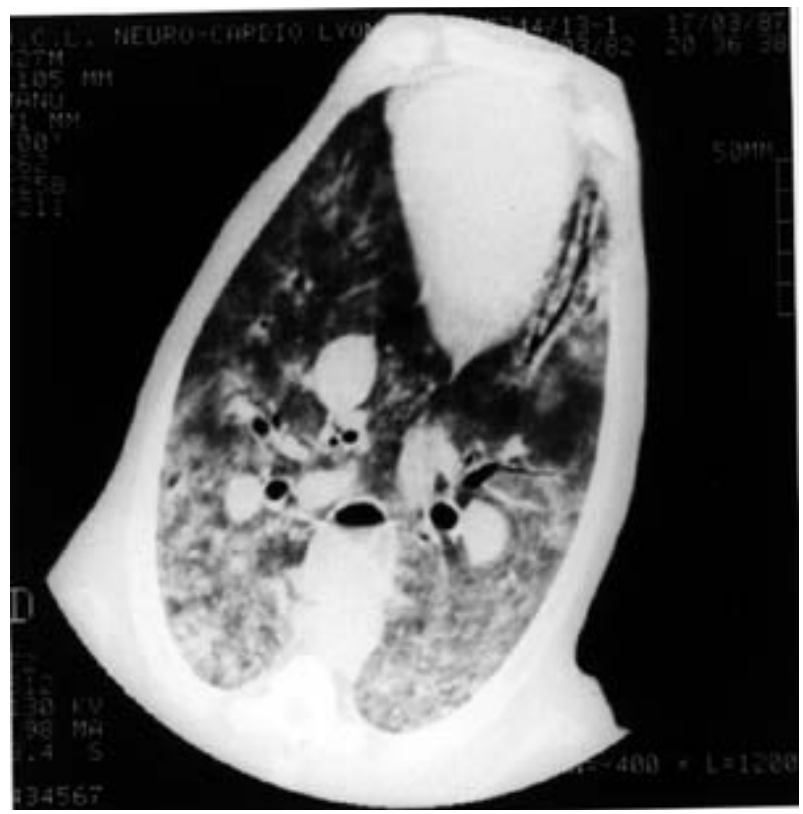

Fig. 2. - High resolution computed tomography (HRCT) performed in adult sheep, showing thickening of the interlobular septa and peribronchiolar areas, bronchiectasis, and diffuse nodular opacities.

The chronically infected adult sheep again showed varying intensity of lesions: sheep A had no significant abnormalities on HRCT; sheep B showed diffuse groundglass opacities, and sheep $\mathrm{C}$, which had advanced disease with severe symptoms, showed a thickening of interlobular septa and peribronchiolar areas, bronchiectasis and diffuse nodular opacities (fig. 2). The adult sheep all showed typical histological lesions of visnamaedi virus [4].

\section{Discussion}

This study showed that HRCT was superior to conventional radiography for the early detection of lung lesions induced by lentiviral infection of newborn lambs, while chest radiography only detected interstitial lung disease at a more advanced stage. HRCT features of a variety of diffuse infiltrative lung diseases have been reported [10-13], and the diagnostic value of HRCT for diffuse interstitial lung disease is well established [14-18]. HRCT visualizes the secondary pulmonary lobules, and even intralobular structures $[19,20]$, and can reveal abnormalities in patients with normal chest radiography in a number of chronic infiltrative lung diseases, including sarcoidosis [21] and silicosis [22].

To obtain HRCT scans, animals must be restrained for considerable periods, and we chose i.v. barbiturate anaesthesia to minimize stress. This method induces a decrease in pulmonary ventilation and blood pressure, and a considerable reduction of muscular tonicity, which all contribute to improved resolution but which also cause a decrease in pulmonary volume, with a concomitant increase in density of the pulmonary parenchyma. An abnormal scan of one uninfected animal was probably due to this effect, exacerbated by a dorsal position during induction of anaesthesia.

Although the histological lesions in experimentally infected sheep are much milder than the typical latestage maedi lesions, the HRCT images are quite characteristic. These lesions resemble those occurring early in spontaneous infection (pre-maedi lesions) [4], with a predominance of peribronchovascular lymphoid nodules. Comparable minor histological alterations can give rise to computed tomographic (CT) abnormalities in human disease [10, 11, 18, 23]. MülLER et al. [24] found a good correlation between CT scans and the gravity of open lung biopsy lesions for 12 patients with idiopathic pulmonary fibrosis. Generally, the HRCT scans of the sheep in the present study also correlated with the histology of autopsy specimens, although one adult sheep with major lesions and positive conventional radiography showed no significant CT abnormality. The ability of HRCT to indicate minor lesions in experimentally infected lambs was good, despite the increased density as a result of anaesthesia, but conventional chest radiography should be included for adult animals with advanced disease. Collie et al. [25] compared physiopathological changes in carbon monoxide transfer factor and morphometric analysis during ovine lymphoid interstitial pneumonia induced by visna-maedi virus, and found that measurements of transfer factor were more sensitive as a functional index of disease progression, and abnormal values were obtained even in sheep considered clinically normal with little or no morphometric evidence of lung disease.

A combination of these two techniques should provide means for the horizontal study of experimentally induced and natural ovine lung pathogenesis by lentivirus. Such studies are highly relevant to the assessment of histogenesis in lentiviral diseases.

In this study, we examined the potential of HRCT for evaluating the evolution of tissue lesions in a lentivirusassociated chronic interstitial lung disease in sheep, which may provide an experimental model for human lentiviral pulmonary pathology.

Our observations suggest that any patients suspected 
of presenting human immunodeficiency virus (HIV)related lung disease should be examined by high resolution computed tomography in addition to simple chest radiography to optimize detection of abnormalities.

\section{References}

1. Narayan O, Clements JE. Biology and pathogenesis of lentiviruses. J Gen Virol 1989; 70: 1617-1639.

2. Haase AT. Pathogenesis of lentivirus infections. Nature 1986; 322: 130-136.

3. Georgsson G, Palson PA. The histopathology of maedi. Vet Pathol 1971; 8: 63-80.

4. Mornex JF, Lena P, Loire R, et al. Lentivirus-induced interstitial lung disease: pulmonary pathology in sheep naturally infected by the visna-maedi virus. Vet Res 1994 ; 25: 478-488.

5. Lairmore MD, Rosadio RH, DeMartini JC. Ovine lentivirus lymphoid interstitial pneumonia: rapid induction in neonatal lambs. Am J Pathol 1986; 125: 173-181.

6. Cordier G, Guigen F, Cadore JL, Jacquier MF, Mornex JF. Characterization of the lymphocytic alveolitis in visna-maedi virus-induced interstitial lung disease of sheep. Clin Exp Immunol 1992; 90: 18-24.

7. Cadoré JL, Guigen F, Cordier G, et al. Early events in the experimental interstitial lung disease induced in sheep by the visna-maedi virus. Immunol Lett 1994; 39: 39-43.

8. Cordier G, Cozon G, Greenland T, et al. In vivo activation macrophages in ovine lentivirus infection. Clin Immunol Immunopathol 1990; 55: 355-367.

9. Lyon M, Huppert J. Depression of reverse transcriptase activity by hybridoma supernatants: a potential problem in screening for retroviral contamination. Biochem Biophys Res Commun 1983; 112: 265-272.

10. Müller NL, Miller RR. Computed tomography of chronic diffuse infiltrative lung disease. Am Rev Respir Dis 1990; 142: 1440-1448.

11. Murata K, Khan A, Herman PG. Pulmonary parenchymal disease: evaluation with high-resolution CT. Radiology 1989; 170: 629-635.

12. Bergin CJ, Müller NL. CT in the diagnosis of interstitial lung disease. Am J Roentgenol 1985; 145: 505-510.
13. Swensen SJ, Aughenbaugh GL, Douglas WW, Myers JL. High-resolution CT of the lungs: findings in various pulmonary diseases. Am J Roentgenol 1992; 158: 971-979.

14. Bergin CJ, Coblentz CL, Chiles C, Bell DY, Castellino RA. Chronic lung diseases: specific diagnosis by using CT. Am J Roentgenol 1989; 152: 1183-1188.

15. Hansell DM, Kerr IH. The role of high resolution computed tomography in the diagnosis of interstitial disease. Thorax 1991; 46: 77-84.

16. Müller NL. Clinical value of high-resolution CT in chronic diffuse lung disease. Am J Roentgenol 1991; 157: 1163-1170.

17. Nishimura K, Izumi T, Kitaichi M, Nagai S, Itoh H. The diagnostic accuracy of high-resolution computed tomography in diffuse infiltrative lung diseases. Chest 1993; 104: 1149-1155.

18. Godwin JD, Holt RM. Imaging of interstitial lung disease. Semin Respir Crit Care Med 1994; 15: 10-36.

19. Bergin CJ, Roggli V, Coblentz C, Chiles C. The secondary pulmonary lobule: normal and abnormal CT appearances. Am J Roentgenol 1988; 151: 21-25.

20. Nishimura K, Kitaichi M, Izumi T, Itoh H. Diffuse panbronchiolitis: correlation of high resolution $\mathrm{CT}$ and pathologic findings. Radiology 1992; 184: 779-785.

21. Müller NL, Mawson JB, Mathieson JR, Abboud R, Ostrow DN, Champion P. Sarcoidosis: correlation of extent of disease at CT with clinical, functional, and radiographic findings. Radiology 1989; 171: 613-618.

22. Begin R, Ostiguy G, Fillion R, Colman N. Computed tomography scan in the early detection of silicosis. Am Rev Respir Dis 1991; 144: 697-705.

23. Gruden JF, Webb WR, Warnock M. Centrilobular opacities in the lung on high resolution CT: diagnostic considerations and pathologic correlation. Am J Roentgenol 1994; 162: 569-574.

24. Müller NL, Miller RR, Webb WR, Evans KG, Ostrow DN. Disease activity in idiopathic pulmonary fibrosis: CT and pathologic correlation. Radiology 1987; 165: 731-734.

25. Collie DDS, Warren PM, Begara I, Lujan L, Watt NJ. Pathophysiologic correlations in lymphoid interstitial pneumonia. Am J Respir Crit Care Med 1994; 149: 15751582. 